\title{
PEG-coated gold nanoparticles attenuate $\beta$-adrenergic receptor-mediated cardiac hypertrophy
}

This article was published in the following Dove Press journal:

International Journal of Nanomedicine

3 July 2017

Number of times this article has been viewed

\section{Yuhui Qiao \\ Baoling Zhu \\ Aiju Tian \\ Zijian Li}

Department of Cardiology, Institute of Vascular Medicine, Peking University Third Hospital, Key Laboratory of Cardiovascular Molecular Biology and Regulatory Peptides, Ministry of Health, Key Laboratory of Molecular Cardiovascular Sciences, Ministry of Education and Beijing Key Laboratory of Cardiovascular Receptors Research, Beijing, People's Republic of China
Correspondence: Zijian Li

Department of Cardiology, Institute of Vascular Medicine, Peking University Third Hospital, Key Laboratory of Cardiovascular Molecular Biology and Regulatory Peptides, Ministry of Health, Key Laboratory of Molecular Cardiovascular Sciences, Ministry of Education and Beijing Key Laboratory of Cardiovascular Receptors Research, 49 North Garden Road, Haidian, Beijing I00191, People's Republic of China

Email lizijian@bjmu.edu.cn
Abstract: Gold nanoparticles (AuNPs) are widely used as a drug delivery vehicle, which can accumulate in the heart through blood circulation. Therefore, it is very important to understand the effect of AuNPs on the heart, especially under pathological conditions. In this study, we found that PEG-coated AuNPs attenuate $\beta$-adrenergic receptor ( $\beta$-AR)-mediated acute cardiac hypertrophy and inflammation. However, both isoproterenol, a non-selective $\beta$-AR agonist, and AuNPs did not induce cardiac function change or cardiac fibrosis. AuNPs exerted an anti-cardiac hypertrophy effect by decreasing $\beta_{1}$-AR expression and its downstream ERK1/2 hypertrophic pathway. Our results indicated that AuNPs might be safe and have the potential to be used as multi-functional materials (drug carrier systems and anti-cardiac hypertrophy agents).

Keywords: AuNPs, cardiac hypertrophy, $\beta$-adrenergic receptor, ERK1/2 signaling pathway

\section{Background}

Along with the advances in nanotechnology, nanoparticles have been applied widely in biomedicine. ${ }^{1,2}$ In particular, gold nanoparticles (AuNPs) are a potential candidate for the development of diagnostic and therapeutic methods, due to their unique physical, chemical, optical, and pharmacological properties. For example, gold cores are inert, stable, biocompatible, and have low toxicity. In addition, AuNPs are easy to prepare and functionalize. ${ }^{3,4}$ Therefore, AuNPs have great potential for many biomedical applications, such as drug or protein delivery, gene transfection, cancer therapy, biomedical imaging, bio-labeling, and molecular diagnostic tools. Furthermore, the surface of AuNPs can be modified to improve specificity and safety of its application in clinical or research. ${ }^{5,6}$ Since AuNPs have shown great potential for wide application in diagnosis and treatment of diseases, it is important to evaluate the safety of AuNPs in the diseases.

Cardiac diseases have been the leading cause of death worldwide. ${ }^{7}$ AuNPs are widely used in the diagnosis and treatment of cardiac diseases. ${ }^{8-11}$ However, there have been only a few studies that examined the effect of AuNPs on the heart. So it is necessary to investigate the safety of AuNPs for the heart under both physiological and pathological conditions. Our previous study proved the safety of AuNPs under physiological conditions, ${ }^{12}$ so we focused on the safety of AuNPs for the heart under pathological conditions in the present study.

Cardiac hypertrophy is an important pathological basis for various heart diseases and is an independent risk factor for morbidity and mortality of heart failure. ${ }^{13}$ The safety of AuNPs in cardiac hypertrophy is still unclear. A key factor in cardiac 
hypertrophy is the over-activation of $\beta$-adrenergic receptor $(\beta-A R)^{14}$ and $\beta$-blockers have been one of the standardized therapeutic drugs for heart failure in clinical settings. ${ }^{15}$ Thus isoproterenol (ISO), the agonist of $\beta$-AR, has been widely used to establish the animal model of cardiac hypertrophy. ${ }^{16,17}$ ISO is reported to induce both chronic and acute cardiac hypertrophy in animal experiments. The chronic cardiac hypertrophy model is used to simulate the chronic progression of heart remodeling in some chronic cardiovascular diseases such as hypertension. ${ }^{18}$ The acute cardiac hypertrophy model reflects cardiac remodeling following acute cardiac injuries. ${ }^{19}$ The safety of AuNPs in ISO-induced chronic cardiac hypertrophy model has been demonstrated in our previous study. ${ }^{20}$ Thus, in the present study, the safety of AuNPs in ISO-induced acute cardiac hypertrophy model was investigated.

The results in this study indicated that the accumulation of AuNPs in the heart depends on their size and the accumulation of AuNPs in the heart attenuates $\beta$-AR-mediated acute cardiac hypertrophy and inflammation through decrease of $\beta_{1}$-AR expression and its downstream ERK1/2 hypertrophy signaling pathway. These novel findings will be helpful for the wider application of AuNPs in cardiac diseases.

\section{Methods}

\section{Characterization of the AuNPs}

Three different sizes (13, 30, and $50 \mathrm{~nm})$ of PEG-coated AuNPs were used in this experiment (Nanocs Inc., New York, NY, USA). The morphology size and aggregation state of the AuNPs were evaluated using transmission electron microscopy (JEM-200CX; Jeol, Ltd., Tokyo, Japan) and Multiskan GO (Thermo Scientific, Ltd, Waltham, MA, USA). The PEG-coated AuNP suspension was sonicated for $5 \mathrm{~min}$ before use.

\section{Establishment of animal model}

Our investigation was approved by the Biomedical Research Ethics Committee of Peking University (LA 2010-048) and strictly adhered to the American Physiological Society's "Guiding Principles in the Care and Use of Vertebrate Animals in Research and Training”. Male FVB/N mice (10-12 weeks) were obtained from laboratory animal department of Peking University Health Science Center. Mice were housed in groups of four and maintained on a $12 \mathrm{~h}$ dark/light cycle in a room with controlled temperature $\left(25^{\circ} \mathrm{C} \pm 2^{\circ} \mathrm{C}\right)$. Mice had free access to food and water. Cardiac hypertrophy model was established by subcutaneous injection of ISO (200 mg/kg/day, dissolved in saline [Sigma-Aldrich, St Louis, MO, USA]) for 3 consecutive days.
There were five groups in total (eight to ten mice in each group): i) control group: daily administration of saline for 3 days; ii) ISO group: daily subcutaneous administration of ISO (200 mg/kg/day) for 3 days; iii) ISO $+13 \mathrm{~nm}$ AuNPs group: daily subcutaneous administration of ISO (200 mg/kg/day) for 3 days, $540 \mu \mathrm{g} / \mathrm{kg}$ AuNPs of $13 \mathrm{~nm}$ were injected into the tail vein on the same days after ISO injections; iv) ISO +30 nm AuNPs group: daily subcutaneous administration of ISO (200 mg/kg/day) for 3 days, $540 \mu \mathrm{g} / \mathrm{kg}$ AuNPs of $30 \mathrm{~nm}$ were injected into the tail vein on the same days after ISO injections; v) ISO +50 nm AuNPs group: daily subcutaneous administration of ISO (200 mg/kg/day) for 3 days, $540 \mu \mathrm{g} / \mathrm{kg}$ AuNPs of $50 \mathrm{~nm}$ were injected into the tail vein on the same days after ISO injections. The content of AuNPs of all three sizes $(13,30$, and $50 \mathrm{~nm})$ was $0.01 \% \mathrm{Ag} / \mathrm{mL}$. The volume of injection was adjusted to $5 \mu \mathrm{L} / \mathrm{g}$ of mice weight. The PEGylated AuNP suspension was sonicated for $5 \mathrm{~min}$ before use to make the AuNPs disperse adequately. The treatment of animals in each group is shown in Table 1.

\section{Echocardiographic analysis}

Echocardiography analysis was performed 1 day after the last injection. Mice were anesthetized with 1.5\% isoflurane (Baxter International Inc., Deerfield, IL, USA). Echocardiographic images were obtained by the Visualsonics high-resolution Vevo 770 system (VisualSonics, Inc., Toronto, ON, Canada). Two-dimensional short-axis views were obtained at the level of the papillary muscle. The diastolic left ventricular posterior wall thickness (LVPW;d) and systolic left ventricular posterior wall thickness (LVPW;s) were measured to calculate the ejection fraction (EF) and fractional shortening (FS). All measurements were averaged from three consecutive cardiac cycles. Cardiac systolic function was represented by the values of EF and FS. Doppler echocardiograms were captured via an apical four chamber view. Transmitral flow Doppler was obtained through mitral flow center and two characteristic E wave and A wave were obtained. Tissue Doppler images were obtained through the mitral annulus and Doppler velocities E' and A' were obtained. E/A, E'/A',

Table I Treatment of animals in each group

\begin{tabular}{lll}
\hline Group & ISO & AuNPs \\
\hline Con & - & - \\
ISO & $200 \mathrm{mg} / \mathrm{kg} / \mathrm{d}, 3 \mathrm{~d}$ & - \\
ISO +13 nm AuNPs & $200 \mathrm{mg} / \mathrm{kg} / \mathrm{d}, 3 \mathrm{~d}$ & $13 \mathrm{~nm} \mathrm{AuNPs}, 540 \mu \mathrm{g} / \mathrm{kg} / \mathrm{d}, 3 \mathrm{~d}$ \\
ISO +30 nm AuNPs & $200 \mathrm{mg} / \mathrm{kg} / \mathrm{d}, 3 \mathrm{~d}$ & $30 \mathrm{~nm} \mathrm{AuNPs}, 540 \mu \mathrm{g} / \mathrm{kg} / \mathrm{d}, 3 \mathrm{~d}$ \\
ISO +50 nm AuNPs & $200 \mathrm{mg} / \mathrm{kg} / \mathrm{d}, 3 \mathrm{~d}$ & $50 \mathrm{~nm} \mathrm{AuNPs}, 540 \mu \mathrm{g} / \mathrm{kg} / \mathrm{d}, 3 \mathrm{~d}$ \\
\hline
\end{tabular}

Abbreviations: AuNPs, gold nanoparticles; ISO, isoproterenol; Con, control; d, days. 
and $\mathrm{E} / \mathrm{E}$ ' ratios were calculated to evaluate cardiac diastolic function. The average of three consecutive cardiac cycles was taken for each parameter. Echocardiography procedures were performed in accordance with the guideline of American Society of Echocardiography.

\section{Quantitative histological analysis}

Mice were anesthetized and sacrificed after echocardiography analysis. The hearts were excised and weighed immediately after being washed with cold PBS. The cardiac tissues for histological and immunohistochemistry analysis were fixed with $4 \%$ paraformaldehyde for $12 \mathrm{~h}$, dehydrated in $20 \%$ sucrose for $24 \mathrm{~h}$, and then embedded in paraffin. Serial sections ( $5 \mu \mathrm{m}$ thick) were stained with hematoxylin and eosin stain (H\&E) for morphological analysis and picrosirius red was used for the detection of fibrosis. For morphometric analysis, photographs of left ventricular sections cut from the same location of each heart were observed under $4 \times, 200 \times$, and 400× magnification, respectively (Leica Microsystems Imaging Solutions Ltd., Wetzlar, Germany). Myocyte crosssectional area was measured by Image Pro Plus using the photographs under $400 \times$ magnification. Interstitial fibrosis was visualized with picrosirius red staining, and the cardiac fibrosis volume fraction was calculated as the ratio of the stained fibrotic area to the total myocardial area.

\section{Western blot analysis}

The cardiac tissues were cracked by tissue homogenizer and ultrasonic unit. After centrifugation (12,000 rpm, $15 \mathrm{~min}$, $4^{\circ} \mathrm{C}$ ), the protein content of supernatant was determined by BCA protein quantitative method. The loading quantity of samples was $30 \mu \mathrm{g}$. Samples were separated by $12 \%$ SDS-PAGE and transferred to polyvinylidene difluoride membranes. After being blocked, blots were probed with the appropriate primary antibodies overnight at $4^{\circ} \mathrm{C}$, then washed and incubated with horseradish peroxidase (HRP)conjugated secondary antibody. Bands were visualized with a super Western blot sensitivity chemiluminescence detection system (Thermo Fisher Scientific). The conditions of primary and secondary antibodies used for immunoblot analysis are summarized in Table 2.

Table 2 Conditions of first and second antibodies for Western blot

\begin{tabular}{lll}
\hline Target protein & First antibody & Second antibody \\
\hline Phosphorylated ERKI/2 & $\mathrm{I}: 1000$ (cst 4370) & $\mathrm{I}: 3000$ (Rabbit) \\
Total ERKI/2 & $\mathrm{I}: 1000$ (cst 9102) & $\mathrm{I}: 3000$ (Rabbit) \\
EIF5 & $\mathrm{I}: 3000$ (sc282) & $\mathrm{I}: 5000$ (Rabbit) \\
\hline
\end{tabular}

\section{Quantitative real-time polymerase chain reaction (PCR)}

Total RNA was isolated from heart tissues using Trizol Reagent (Thermo Fisher Scientific). The complementary DNA was synthesized using the kit (017317; Promega Corporation, Fitchburg, WI, USA). Relative quantitation by real-time PCR was performed using SYBR Green to detect PCR products in real time with ABI PRISM 7700 Sequence Detection System (Applied Biosystems, Thermo Fisher Scientific). Primer sequences were as follows: EIF 5:5'-CAGAAAAACAAGAGCGAAGACAG-3', $5^{\prime}$-GCTTCCAGAGACAACTCCTCC-3'; TNF- $\alpha: 5^{\prime}$-CC CACGTCGTAGCAAACCA-3'， 5'-ACAAGGTACA ACCCATCGGC-3'; IL-1 $\beta: 5^{\prime}$-TGCCACCTTTTGAC A GTGA T G-3'， 5'-A A GGT C C A C GGGA A A G A CAC-3'; IL-6:5'-CGGCCTTCCCTACTTCACAA-3', 5'-TTCTGCAAGTGCATCATCGT-3'; $\beta 1$-AR:5'-GCC C T T T C GC T A C C A GA G T T - 3', 5' - A C T T GGG GTCGTTGTAGCAG-3'; $\beta 2-A R: 5^{\prime}$-TCGAGCGACTA C A A A C C G T C - 3', , 5' - A A G T C C A G A A C T C GCACCAG-3', ANF: 5'-CTTCCAGGCCATATTG GAG-3'， 5'-GGGGGCATGACCTCATCTT-3'; BNP: 5'-ACAAGATAGACCGGATCGGA-3', 5'-A GCCA GGAGGTCTTCCTACA-3'; CollagenI:5'-GTAACT TCGTGCCTAGCAACA-3', 5'-CCTTTGTCAGAATA CTGAGCAGC-3'; CollagenIII:5'-CCTGGCTCAAAT GGCTCAC-3'; 5'-CAGGACTGCCGTTATTCCCG-3'. PCR was performed under the following conditions: $95^{\circ} \mathrm{C}$ for $2 \mathrm{~min}$, followed by 40 amplification cycles $\left(95^{\circ} \mathrm{C}\right.$ for 15 $\mathrm{s}, 60^{\circ} \mathrm{C}$ for $1 \mathrm{~min}$ ). The $\mathrm{CT}$ (threshold cycle) values obtained for genes of interest were normalized to concurrent measurement of EIF 5 mRNA level, and fold changes were compared to the control.

\section{Inductively coupled plasma-mass spectrometry (ICP-MS)}

The concentrations of AuNPs in tissues were assessed by quantitative inductively coupled plasma mass spectrometry (ICP-MS). Cardiac tissues (approximately $30 \mathrm{mg}$ each) were digested in aqua fortis (nitric acid:hydrochloric acid 3:1). After adjusting the solution volume to $2 \mathrm{~mL}$ using $2 \%$ nitric acid and 1\% hydrochloride acid (1:1), Au content assays were performed using an ELAN DRC-e ICP-MS instrument (PerkinElmer Inc., Waltham, MA, USA).

\section{Statistical analysis}

Data were summarized as means \pm SEM. Differences in data between groups were compared using Prism 5 (GraphPad Software Inc., La Jolla, CA, USA) with one-way ANOVA 
followed by Dunnett's test. Data with $P<0.05$ were considered statistically significant.

\section{Results}

\section{The accumulation of AuNPs in the} mouse heart

To investigate the effect of AuNPs on $\beta$-AR-mediated cardiac remodeling, experiments were designed as shown in the working flow chart, Figure 1A. Firstly, the accumulation of AuNPs was determined by ICP-MS in mouse heart. As shown in Figure 1B, accumulation of AuNPs in the heart was size-dependent. The $13 \mathrm{~nm}$ AuNPs showed the highest accumulation in heart $(1,438+236.9 \mathrm{ng} / \mathrm{g})$ which was extremely high in comparison with that of $30 \mathrm{~nm}$ $(68.76+17.33 \mathrm{ng} / \mathrm{g})$ and $50 \mathrm{~nm}(18.21+4.052 \mathrm{ng} / \mathrm{g})$.

\section{Effects of the AuNPs on cardiac hypertrophy}

The ratio of heart weight to tibia length (HW/TL), the ratio of heart weight to body weight (HW/BW), LVPW;d, myocyte cross-sectional area, ANF, and BNP are all major indicators of cardiac hypertrophy. As shown in Figure 2A and B, ISO markedly increased LVPW; d and AuNPs (13, 30, and $50 \mathrm{~nm}$ ) reversed this process. Similarly, AuNPs (13, 30, and $50 \mathrm{~nm})$ attenuated HW/BW (Figure 2C) and HW/TL (Figure 2D) increased significantly by ISO. Moreover, AuNPs (13, 30, and $50 \mathrm{~nm}$ ) reduced myocyte cross-sectional area (Figure $2 \mathrm{E}$ and F) increased by ISO. AuNPs (13, 30, and $50 \mathrm{~nm}$ ) also decreased the mRNA expression of ANF (Figure 2G) and BNP (Figure 2H).

\section{Effects of the AuNPs on cardiac fibrosis}

Chronic long-term ISO stimulation could cause fibrosis. ${ }^{21}$ Our results indicated that acute short-term ISO stimulation did not induce obvious fibrosis. Furthermore, AuNPs did not affect cardiac fibrosis either (Figure 3A and B). Collagen I and Collagen III are also fibrosis markers. The mRNA expressions of Collagen I (Figure 3C) and Collagen III (Figure 3D) were consistent with the previously mentioned conclusion.

\section{Effects of the AuNPs on cardiac functions}

Assessment of cardiac function is important in cardiac diseases. The left ventricular EF and FS were the most important

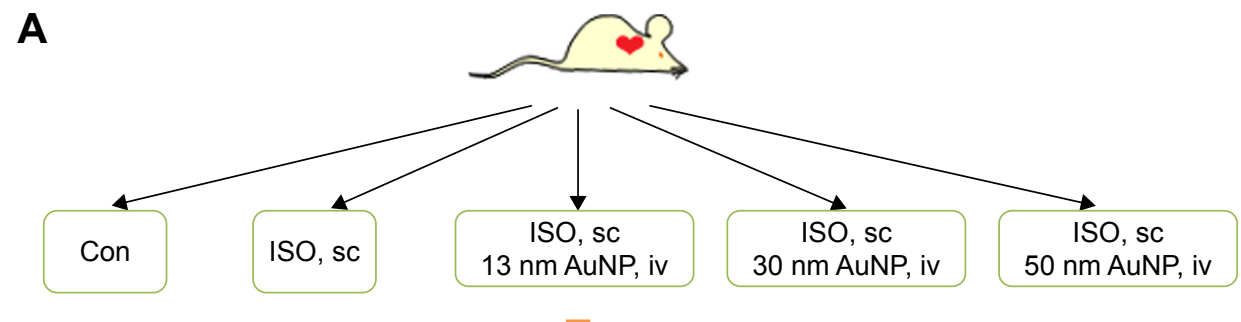

Analysis
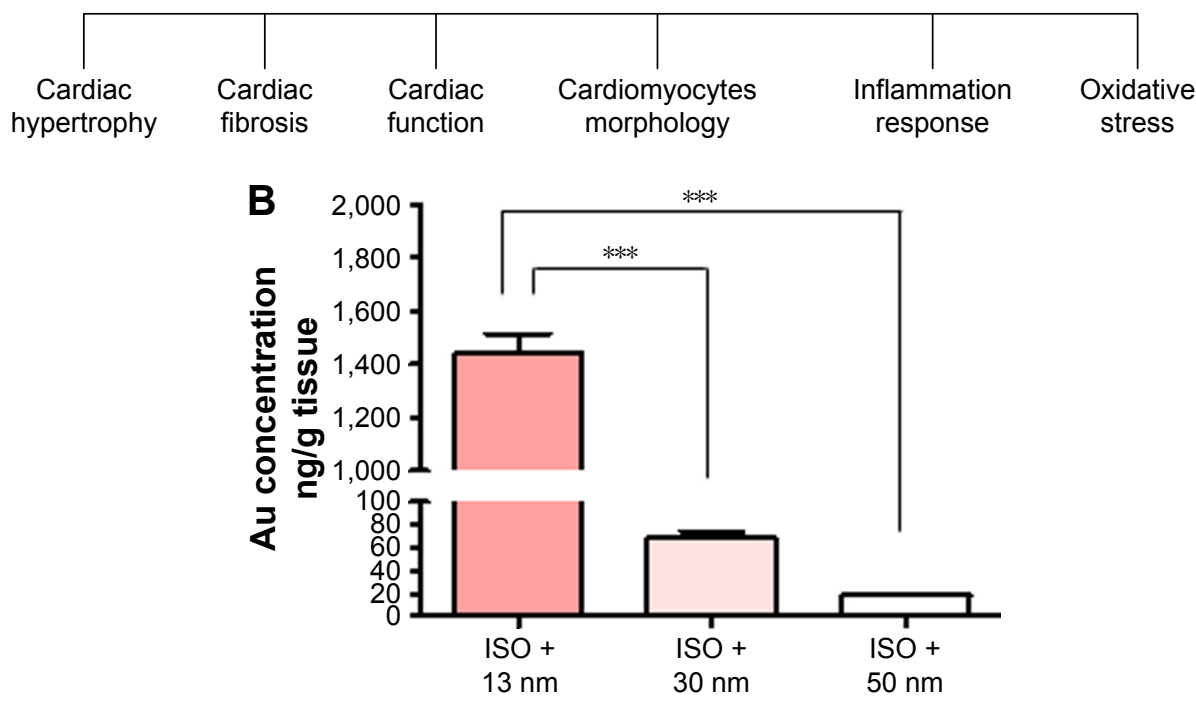

Figure I Experimental flow chart and Au accumulation in heart.

Notes: (A) The experimental flow chart of the present study. (B) The Au content in mouse heart was determined with inductively coupled plasma mass spectrometry. $* * * P<0.001$. Data represent mean \pm SEM.

Abbreviations: AuNPs, gold nanoparticles; ISO, isoproterenol; sc, subcutaneous; iv, intravenous; Con, control. 
A

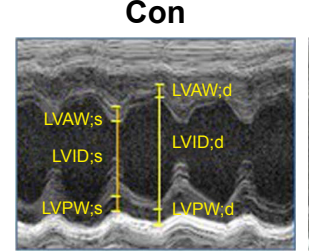

B

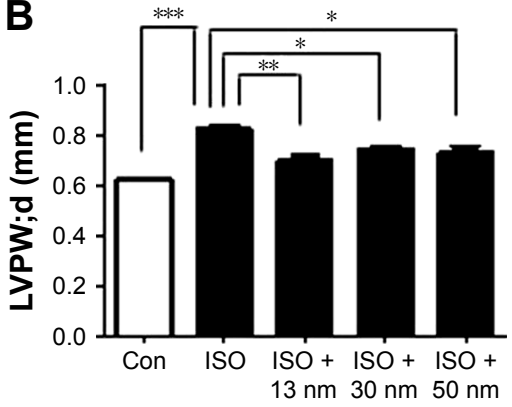

E

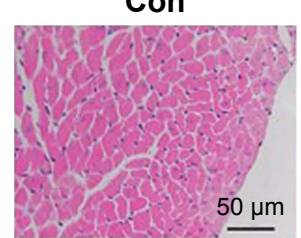

$\mathbf{F}$

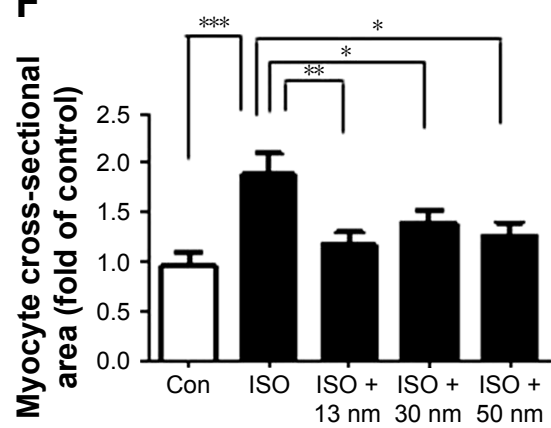

ISO

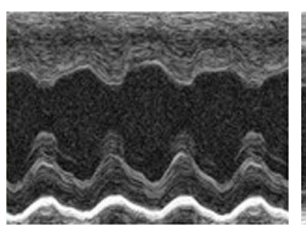

C

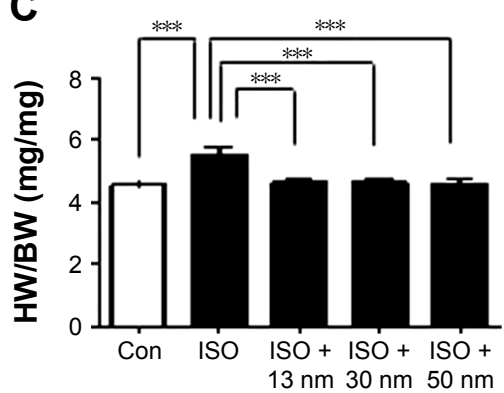

ISO

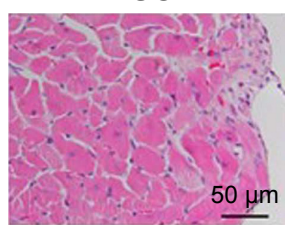

G

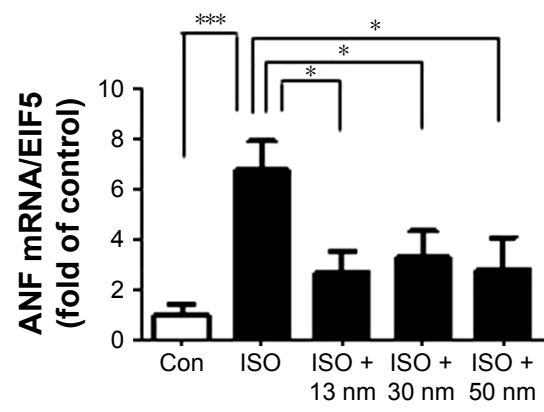

ISO +13 nm

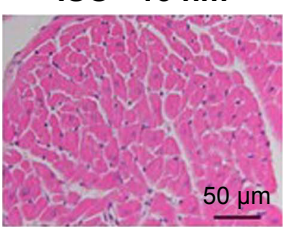

ISO +30 nm

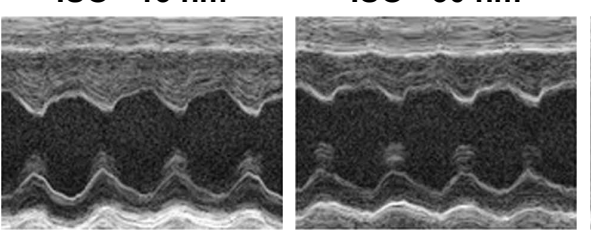

\section{ISO +50 nm}

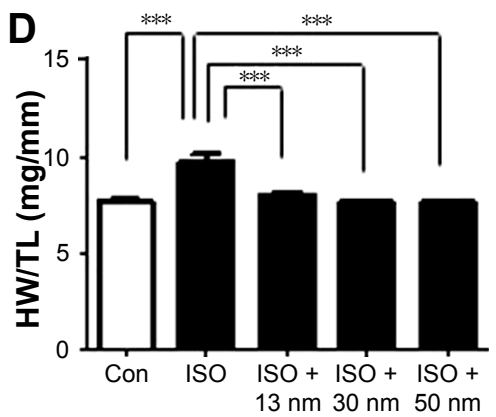

ISO +30 nm

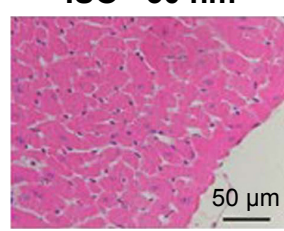

ISO +50 nm

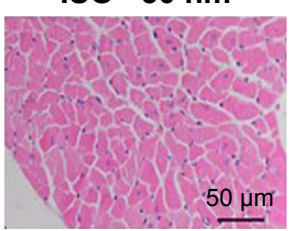

H

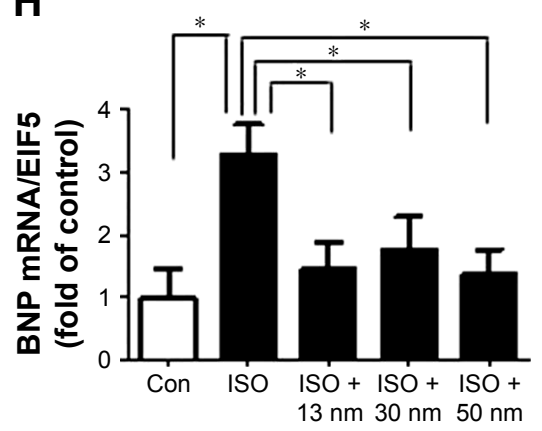

Figure 2 The effects of AuNPs on cardiac hypertrophy.

Notes: $* P<0.05$, $* * P<0.01$, $* * * P<0.001$. (A) Representative M-mode echocardiography images were taken to show left ventricular wall thickness. (B) $Q$ uantitative analysis of diastolic left ventricular posterior wall thickness. (C) Quantitative analysis of HW/BW ratio. (D) Quantitative analysis of HW/TL ratio. Data represent mean \pm SEM. (E) Representative micrographs of myocyte cross-sectional area. (F) Quantitative analysis of myocyte cross-sectional area. (G) Quantitative analysis of ANF mRNA expression. (H) Quantitative analysis of BNP mRNA expression.

Abbreviations: AuNPs, gold nanoparticles; HW/BW, ratio of heart weight to body weight; HW/TL, ratio of heart weight to tibia length; ISO, isoproterenol; Con, control; LVAW;s, systolic left ventricular anterior wall thickness; LVID;s, left ventricular end-systolic inner-diameter; LVPW;s, systolic left ventricular posterior wall thickness; LVAW;d, diastolic left ventricular anterior wall thickness; LVID;d, left ventricular end-diastolic inner-diameter; LVPW; d, diastolic left ventricular posterior wall thickness.

indicators to evaluate the cardiac contraction function. Results showed that the EF and FS were still normal after exposure to ISO. AuNPs (13, 30, and $50 \mathrm{~nm})$ did not affect EF or FS (Figure 4A and B). E/A, E'/A' and E/E' were used to evaluate cardiac diastolic function. Similar to cardiac contraction function, ISO did not affect cardiac diastolic function obviously in this model. AuNPs (13, 30, and $50 \mathrm{~nm})$ did not affect cardiac diastolic function either (Figure 4C-F).

\section{Effects of the AuNPs on $\beta$-AR-mediated IL-6 mRNA expression}

First, H\&E staining showed that ISO induced inflammatory cell infiltration. However, the additional accumulation of
AuNPs in the heart did not aggravate ISO-induced cardiac inflammation (Figure 5A). Furthermore, inflammatory cytokines TNF- $\alpha$, IL-1 $\beta$, and IL- 6 were detected with realtime PCR. Consistent with cardiac hypertrophy, AuNPs $(13,30$, and $50 \mathrm{~nm})$ significantly inhibited IL-6 production increased by ISO (Figure 5B). In contrast to IL-6, ISO did not increase the production of TNF- $\alpha$ (Figure 5C) and IL-1 $\beta$ (Figure 5D).

\section{Effects of the AuNPs on $\beta$-AR mRNA expression}

It has been reported that chronic ISO stimulation downregulated the expression of both $\beta_{1}$-AR and $\beta_{2}$-AR. ${ }^{22}$ In this study, 
A

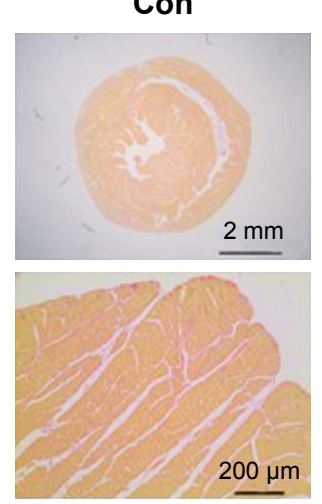

ISO

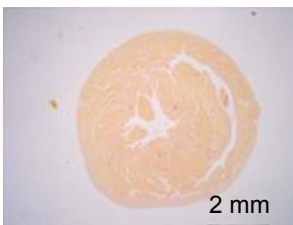

ISO +13 nm

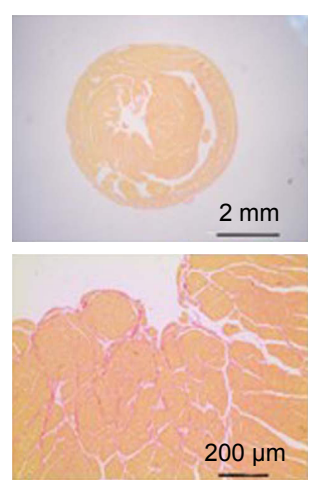

ISO +30 nm

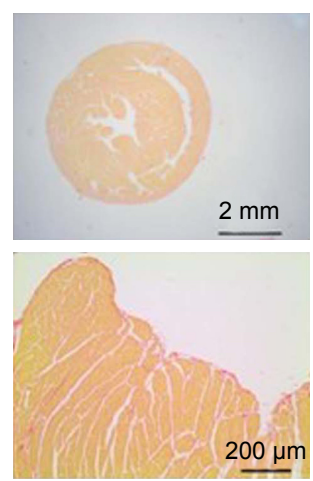

ISO +50 nm

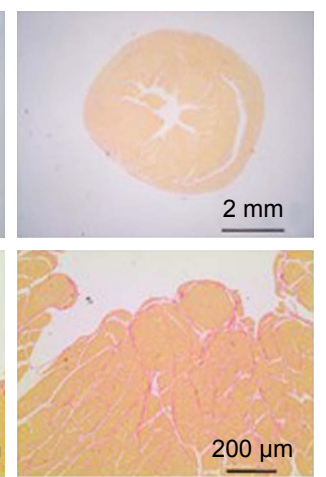

B
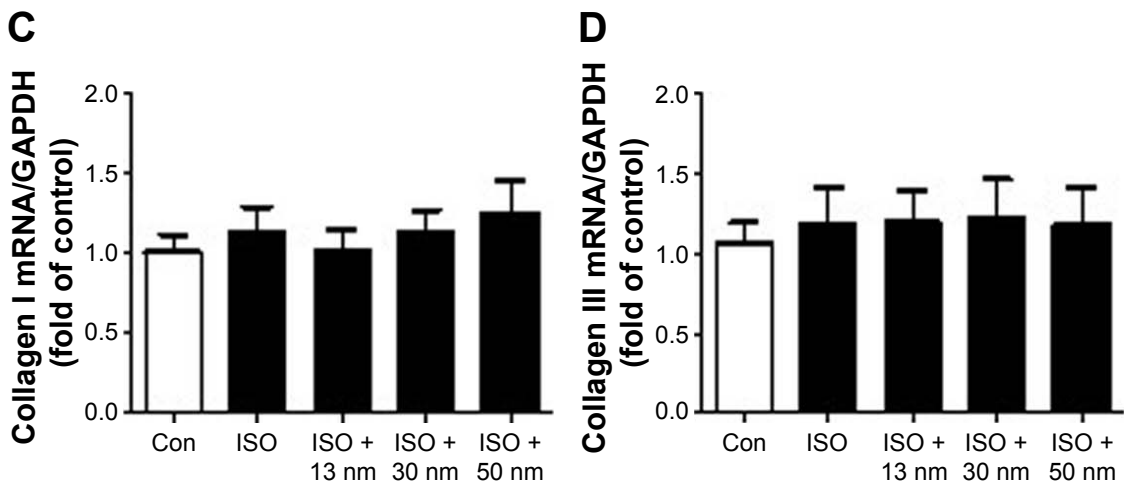

Figure 3 The effects of AuNPs on cardiac fibrosis.

Notes: (A) Representative micrographs of picrosirius red-stained sections of the ventricle. Red parts represent collagen. (B) Quantification of cardiac interstitial collagen content from picrosirius red-stained sections with results expressed as the ratio of collagen area to heart area. There is no significance among all the groups. (C) The mRNA expression of Collagen I in the heart tissue. (D) The mRNA expression of Collagen III in the heart tissue.

Abbreviations: AuNPs, gold nanoparticles; ISO, isoproterenol; Con, control.

the result showed that acute ISO stimulation upregulated $\beta_{1}$-AR but not $\beta_{2}$-AR mRNA expression (Figure $6 \mathrm{~A}$ and $\mathrm{B}$ ). AuNPs $(13,30$, and $50 \mathrm{~nm})$ inhibited the upregulation of $\beta_{1}$-AR mRNA expression significantly (Figure 6A) but had no influence on $\beta_{2}$-AR mRNA expression (Figure 6B).

\section{Effects of the AuNPs on $\beta$-AR-mediated ERKI/2 pathway activation}

It is well known that ERK1/2 MAPK pathway plays an important role in $\beta$-AR-mediated cardiac hypertrophy. ${ }^{23,24}$ The results indicated that AuNPs (13, 30, and $50 \mathrm{~nm}$ ) decreased the phosphorylation of ERK1/2 induced by ISO obviously (Figure 7A and B), which is consistent with the function of AuNPs in inhibiting $\beta$-AR-mediated cardiac hypertrophy.

\section{Discussion}

In this study, we investigated the safety of AuNPs in the acute cardiac hypertrophy model induced by large dose of ISO. The result suggested that AuNPs could inhibit cardiac hypertrophy in this model. The mechanism may be related to the inhibition of $\beta_{1}$-AR expression and its downstream signaling pathway, such as inflammation and the phosphorylation of ERK1/2.

Our study indicated that AuNPs (13,30, and $50 \mathrm{~nm}$ ) inhibited the increase of $\beta 1$-AR mRNA expression induced by ISO but not $\beta 2$-AR, which is consistent with the result showing that $\beta$-AR-mediated cardiac hypertrophy is primarily due to the activation of $\beta 1-A R \cdot{ }^{25,26}$ Recent studies have proven that AuNPs could affect the synthesis and function of biological macromolecules. For example, AuNPs could interfere with the synthesis of ribosomal protein. ${ }^{27}$ Further, AuNPs could conjugate to G-protein and affect the activity of G-protein. ${ }^{28}$ These studies suggest that AuNPs may regulate the expression of $\beta 1$-AR and its downstream signaling pathway which reflects the activity of $\beta 1$-AR.

Many studies have suggested that inflammation is involved in cardiac hypertrophy. Pro-inflammatory cytokines such as IL-6, IL-1 $\beta$, and TNF- $\alpha$ promote cardiac hypertrophy. ${ }^{29,30}$ In this study, the mRNA expression of IL-1 $\beta$ and TNF- $\alpha$ did not increase, but the mRNA expression of IL-6 increased after acute ISO treatment. Some studies have 

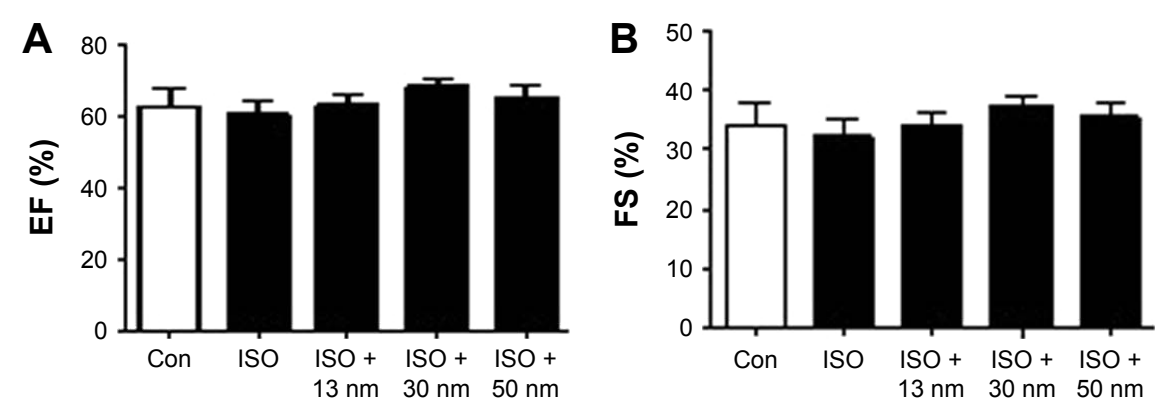

C
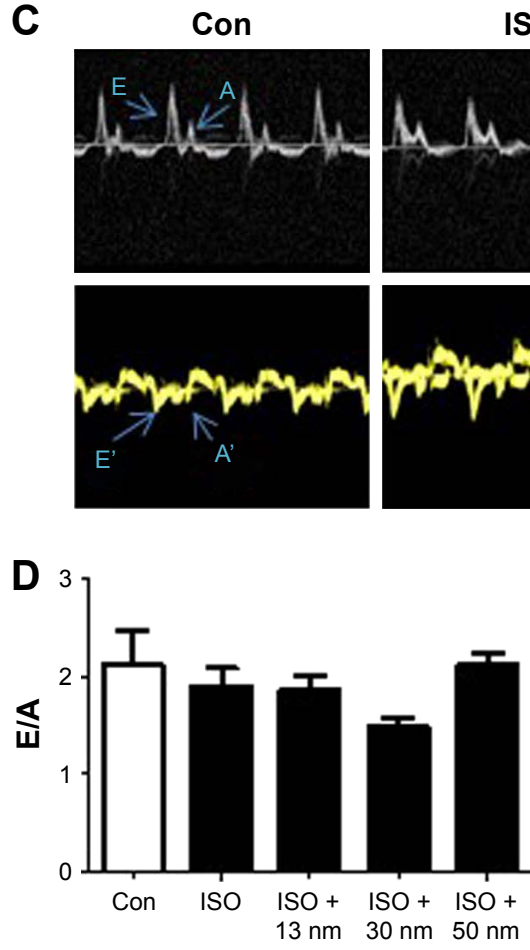

ISO
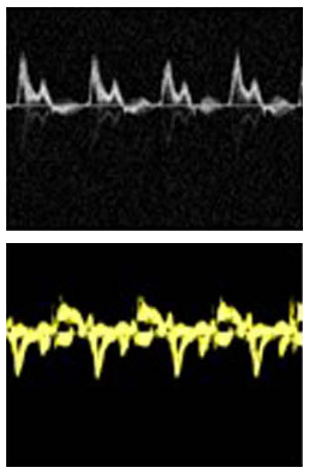

E 1.5
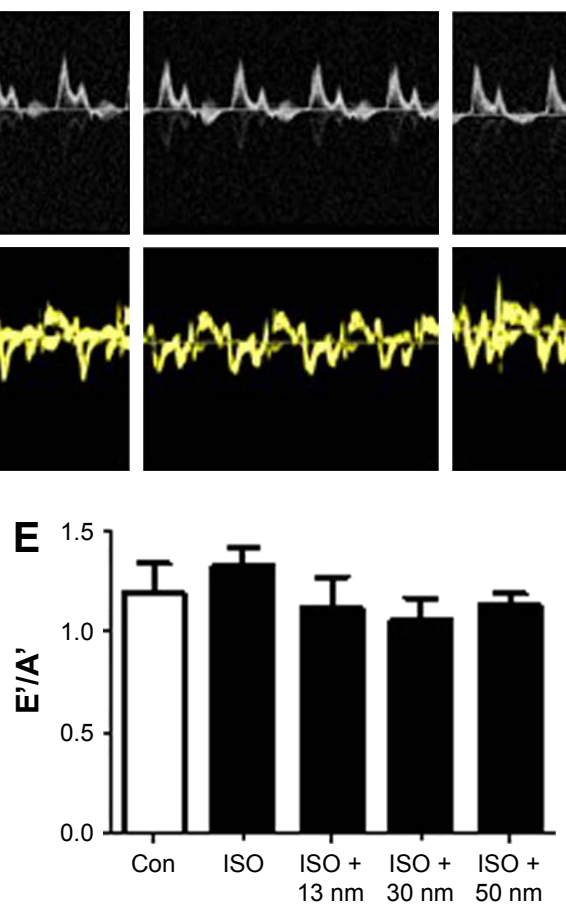

ISO +30 nm

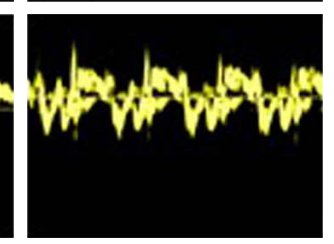

$\mathbf{F}$

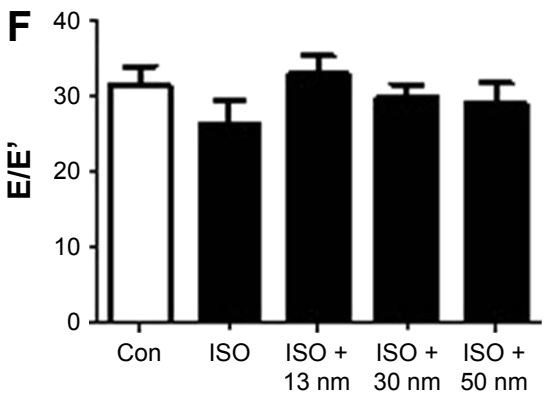

Figure 4 The effects of AuNPs on cardiac function.

Notes: (A) Left ventricular EF and (B) FS were measured to reflect cardiac contraction function. (C) Representative Doppler echocardiographic images. (D) E/A, (E) E'/A' (F) and E/E' ratios were used to reflect cardiac diastolic function. No significance was found.

Abbreviations: EF, ejection fraction; FS, fractional shortening; AuNPs, gold nanoparticles; ISO, isoproterenol; Con, control.

indicated that ISO could increase the expression of IL-6, IL-1 $\beta$, and TNF- $\alpha .{ }^{31,32}$ However, it has also been reported that ISO treatment downregulated TNF- $\alpha$ production and caused no change in IL-6 production..$^{33}$ This suggested that inflammation is a complicated process, and different inflammatory cytokines may have different reactions after $\beta$-receptor activation. In addition, the dose of ISO and the time course of administration may also have an influence on the inflammatory cytokines' production. The specific mechanisms still need to be researched more. It has also been reported that AuNPs of $21 \mathrm{~nm}$ could reduce IL- 6 mRNA level in the fat.$^{34}$ Consistent with the previous study, in our study, AuNPs $(13,30$, and $50 \mathrm{~nm})$ inhibited ISO-increased IL-6 mRNA expression which contributed to the $\beta$-AR-mediated cardiac hypertrophy.
ERK1/2 signaling pathways are important regulators of $\beta 1$-AR-mediated cardiac hypertrophy. ${ }^{35-37}$ In the present study, we found that AuNPs inhibited the phosphorylation of ERK1/2 induced by ISO. In addition, recent work has suggested that ERK1/2 signaling is regulated, at least in part, by oxidative stress ${ }^{38,39}$ and that antioxidants can function to block the activation of ERK1/2 both in vitro and in vivo. ${ }^{40,41}$ While some other studies have shown that AuNPs could suppress oxidative stress and elevate the antioxidant defense system in vivo. ${ }^{42-45}$ So AuNPs may inhibit the phosphorylation of ERK1/2 partly through the inhibition of oxidative stress.

AuNPs $(13,30,50 \mathrm{~nm})$ inhibited ISO-induced cardiac hypertrophy in the present study, but AuNPs have no effect on either the systolic or diastolic functions. It is noteworthy that both the systolic and diastolic functions did not change 


\section{A}
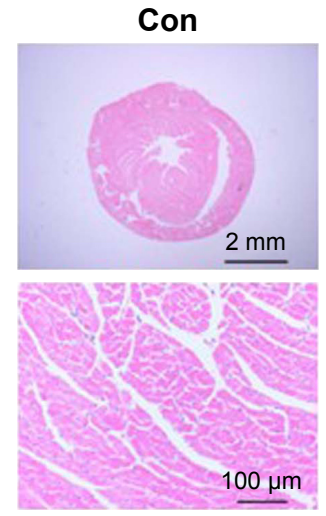

$100 \mu \mathrm{m}$

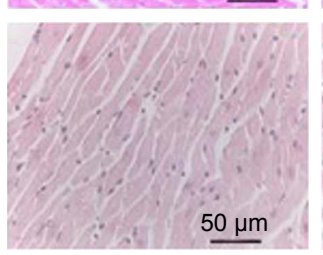

ISO

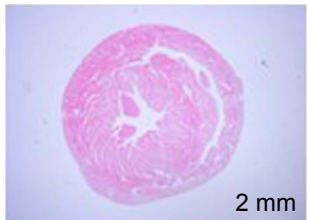

$2 \mathrm{~mm}$

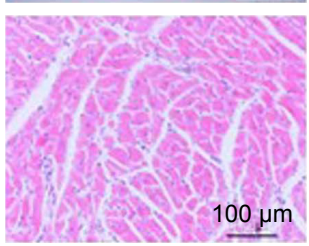

$100 \mu \mathrm{m}$

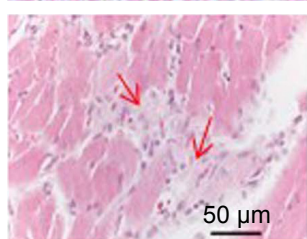

ISO +13 nm
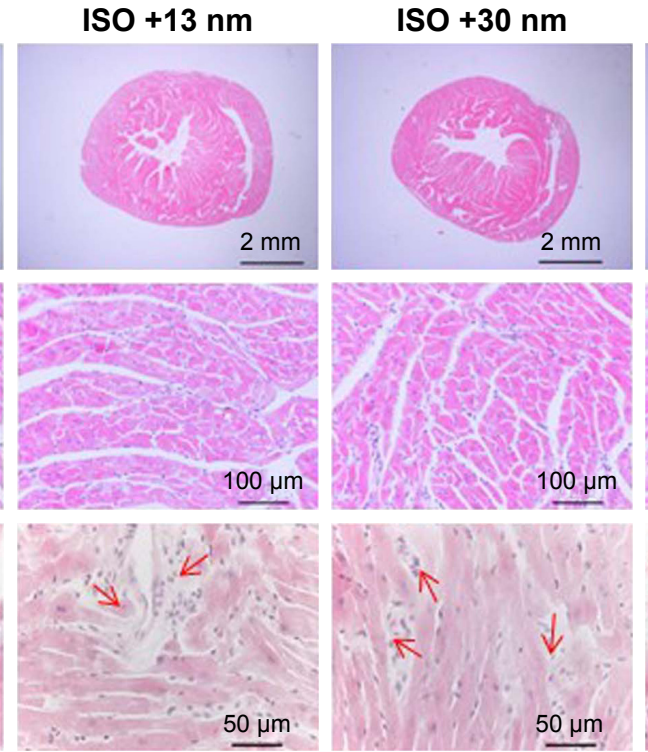

\section{ISO +50 nm}
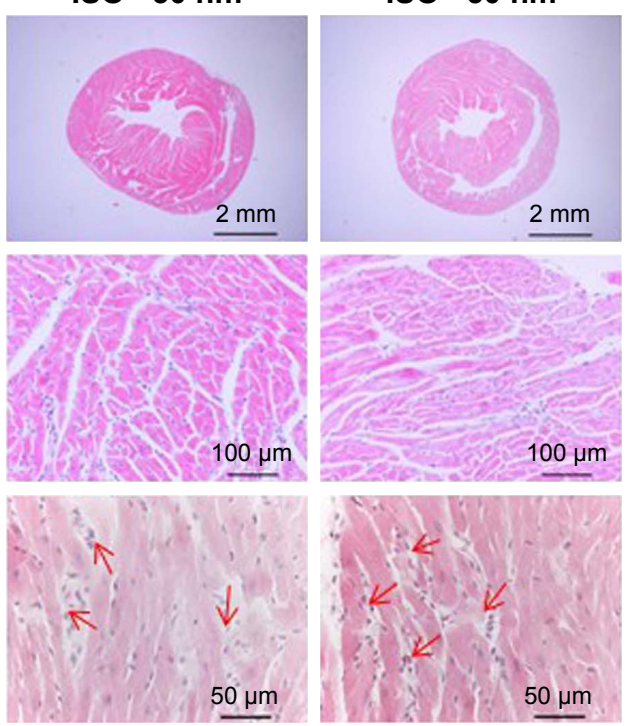

B

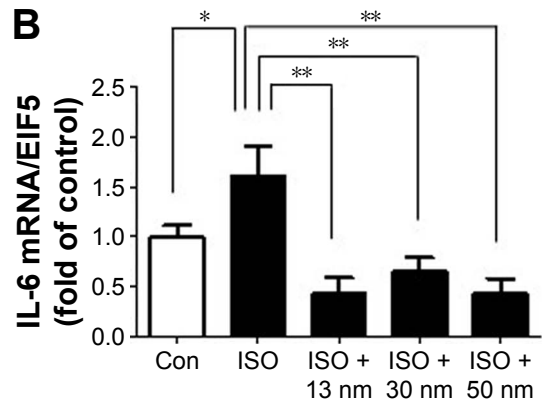

C

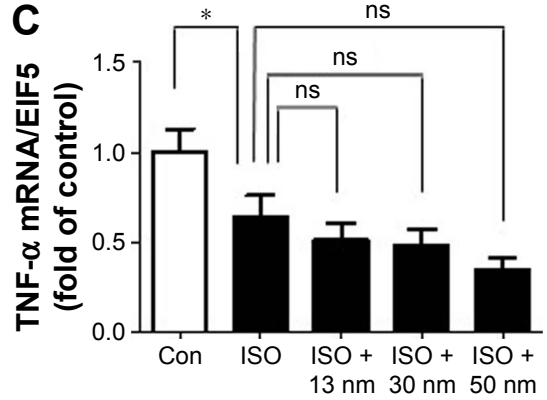

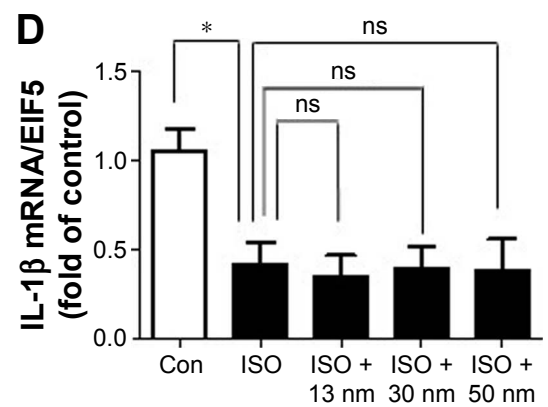

Figure 5 The effects of AuNPs on inflammation in the heart.

Notes: (A) Representative images showing H\&E staining of heart sections. The arrows refer to the infiltrated inflammatory cells. The scale bars of I2.5× images are 2 mm, of $250 \times$ images are $100 \mu \mathrm{m}$, and those of $500 \times$ images are $50 \mu \mathrm{m}$. (B) The mRNA expression of IL-6 in the heart tissue. (C) The mRNA expression of TNF- $\alpha$ in the heart tissue. (D) The mRNA expression of IL-I $\beta$ in the heart tissue. $* P<0.05$, $* * P<0.01$. Data represent mean \pm SEM.

Abbreviations: AuNPs, gold nanoparticles; H\&E, hematoxylin and eosin; ISO, isoproterenol; Con, control; ns, no significance.

A

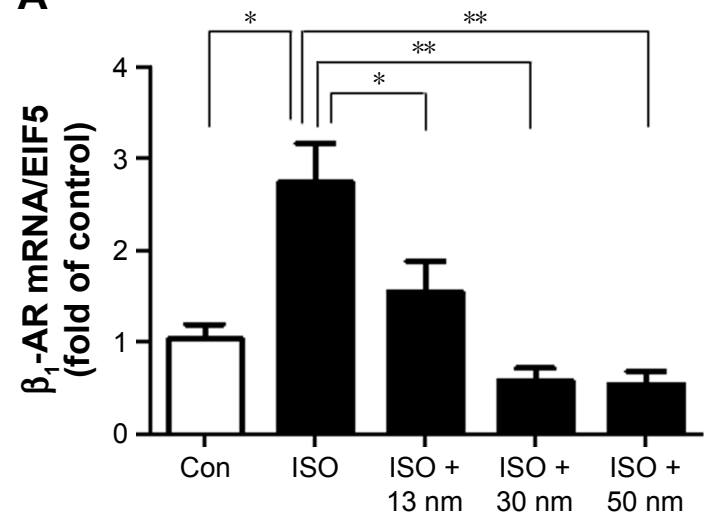

B

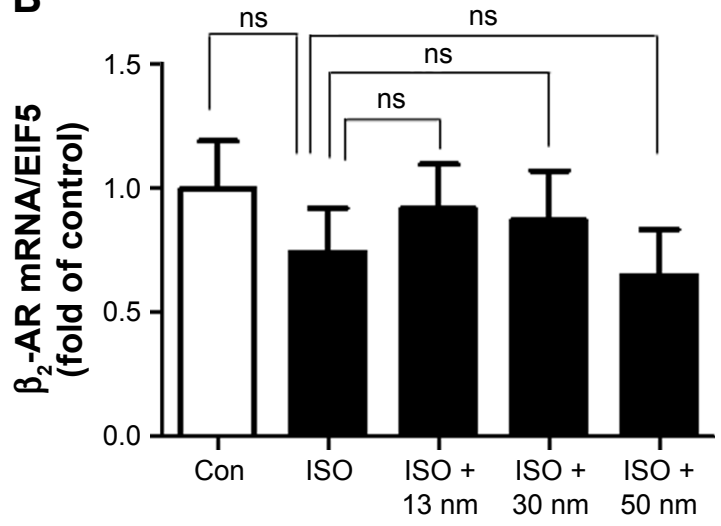

Figure 6 The effects of AuNPs on $\beta$-adrenergic receptor ( $\beta$-AR) mRNA expression in the heart.

Notes: (A) The mRNA expression of $\beta_{1}$-AR in the heart tissue. (B) The mRNA expression of $\beta_{2}$-AR in the heart tissue. $* P<0.05$, $* * P<0.0$ I. Data represent mean \pm SEM. Abbreviations: AuNPs, gold nanoparticles; ISO, isoproterenol; Con, control; ns, no significance. 
A

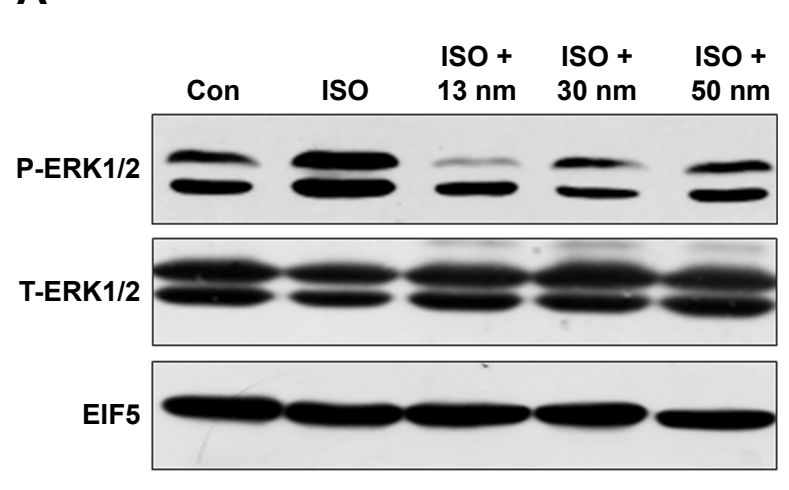

B

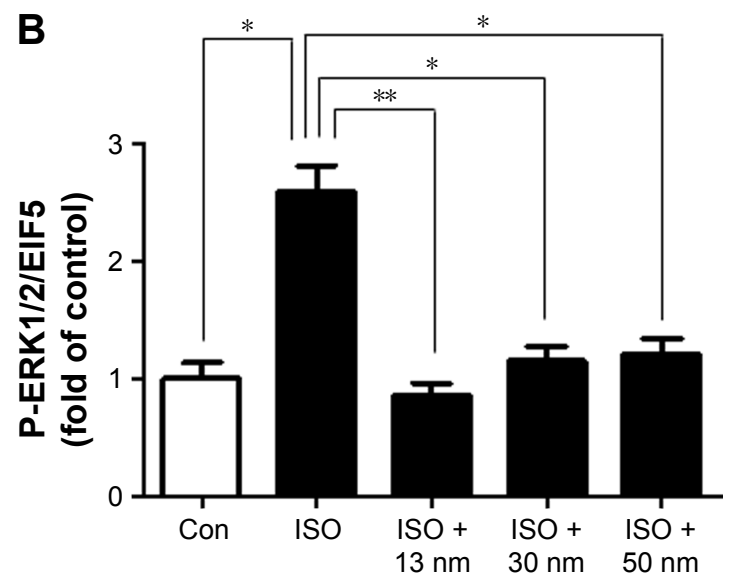

Figure 7 The effects of AuNPs on the phosphorylation of ERKI/2.

Notes: (A) The protein expression of P-ERKI/2 (phosphorylated ERKI/2) and T-ERKI/2 (total ERKI/2) of all the groups. (B) Quantitative analysis of the level of P-ERKI/2 of all the groups. $* P<0.05, * * P<0.01$.

Abbreviations: AuNPs, gold nanoparticles; ISO, isoproterenol; Con, control.

after ISO treatment. The possible reason is that cardiac remodeling is in a compensation stage, so both the systolic and diastolic functions are not damaged in this stage.

There are some differences between the results of all the studies about the toxicity of AuNPs. It is likely due to their modifications, functional attachment of their surfaces, shapes, and sizes. ${ }^{46,47}$ For example, known as a modifying polymer, PEG decreases immunogenicity and increases stability of drugs in the circulatory system. Therefore, the PEG coating reduces the chance of heart toxicity induced by AuNPs. ${ }^{48-50}$

Taken together, our results showed that AuNPs inhibited cardiac hypertrophy mediated by $\beta-A R$, and this effect

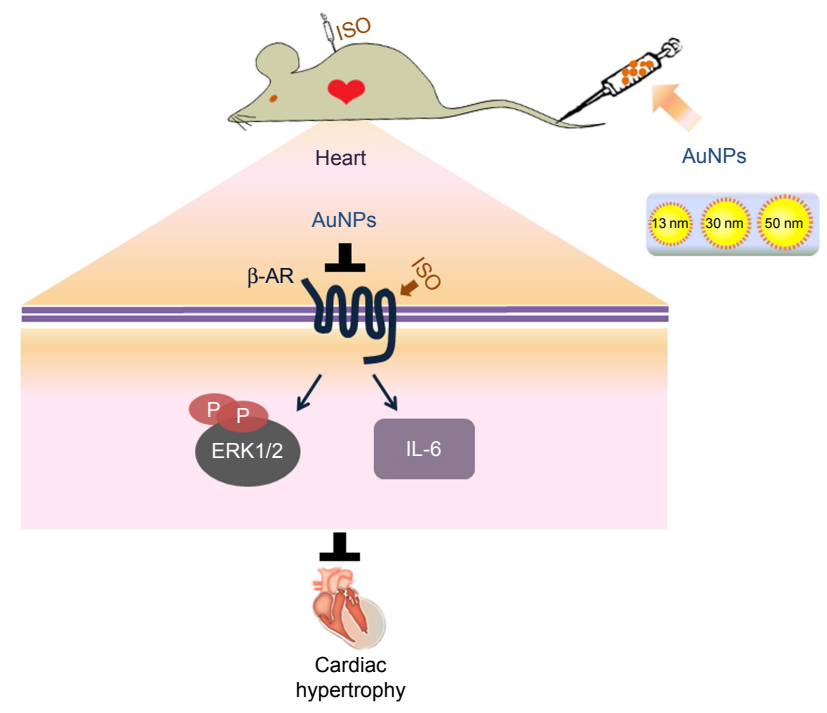

Figure 8 Working model of the effects of AuNPs on $\beta$-adrenergic receptor ( $\beta$-AR)mediated cardiac hypertrophy.

Abbreviations: AuNPs, gold nanoparticles; ISO, isoproterenol. depends on a complex mechanism involving inhibition of $\beta_{1}$-AR expression and its downstream effectors IL- 6 and ERK1/2 (Figure 8). These results raise the hope that AuNPs might be used as multi-functional materials (drug carrier systems and anti-cardiac hypertrophy agents) for cardiac diseases' treatment.

\section{Acknowledgments}

This work was supported by grants from the National Basic Research Program of China (grant no 2014CBA02000), the National Natural Science Foundation of China (81471893, 81270157, 91539123, 81070078), and Beijing Municipal Natural Science Foundation (7172235).

\section{Disclosure}

The authors report no conflicts of interest in this work.

\section{References}

1. Yang Li, Zhang Y, Yan B. Nanotoxicity overview: nano-threat to susceptible populations. Int J Mol Sci. 2014;15(3):3671-3697.

2. Toy R, Bauer L, Hoimes C, Ghaghada KB, Karathanasis E. Targeted nanotechnology for cancer imaging. Adv Drug Deliv Rev. 2014;76: 79-97.

3. Spivak MY, Bubnov RV, Yemets IM, Lazarenko LM, Tymoshok NO, Ulberg ZR. Gold nanoparticles - the theranostic challenge for PPPM: nanocardiology application. EPMA J. 2013;4(1):18.

4. Housni A, Zhao Y. Gold nanoparticles functionalized with block copolymers displaying either LCST or UCST thermosensitivity in aqueous solution. Langmuir. 2010;26(15):12933-12939.

5. Liu A, Ye B. Application of gold nanoparticles in biomedical researches and diagnosis. Clin Lab. 2013;59(1-2):23-36.

6. Mieszawska AJ, Mulder WJ, Fayad ZA, Cormode DP. Multifunctional gold nanoparticles for diagnosis and therapy of disease. Mol Pharm. 2013;10(3):831-847. 
7. Ferguson JF, Allayee H, Gerszten RE, et al. Nutrigenomics, the microbiome, and gene-environment interactions: new directions in cardiovascular disease research, prevention, and treatment: a scientific statement from the American Heart Association. Circ Cardiovasc Genet. 2016;9(3):291-313.

8. Davis ME, Hsieh PC, Takahashi T, et al. Local myocardial insulin-like growth factor 1 (IGF-1) delivery with biotinylated peptide nanofibers improves cell therapy for myocardial infarction. Proc Natl Acad Sci $U S$ A. 2006;103(21):8155-8160.

9. Nagaoka K, Matoba T, Mao Y, et al. A new therapeutic modality for acute myocardial infarction: nanoparticle mediated delivery of pitavastatin induces cardioprotection from ischemia-reperfusion injury via activation of PI3K/Akt pathway and anti-inflammation in a rat model. PLoS One. 2015;10(7):e0132451.

10. Spivak MY, Bubnov RV, Yemets IM, Lazarenko LM, Tymoshok NO, Ulberg ZR. Development and testing of gold nanoparticles for drug delivery and treatment of heart failure: a theranostic potential for PPP cardiology. EPMA J. 2013;4(1):20.

11. Bietenbeck M, Florian A, Sechtem U, Yilmaz A. The diagnostic value of iron oxide nanoparticles for imaging of myocardial inflammation quo vadis? J Cardiovasc Magn Reson. 2015;17:54.

12. Yang C, Tian A, Li Z. Reversible cardiac hypertrophy induced by PEG-coated gold nanoparticles in mice. Sci Rep. 2016;6:20203.

13. Okin PM, Devereux RB, Nieminen MS, et al. Electrocardiographic strain pattern and prediction of new-onset congestive heart failure in hypertensive patients: the losartan intervention for endpoint reduction in hypertension (LIFE) study. Circulation. 2006;113(1):67-73.

14. Shimizu I, Minamino T. Physiological and pathological cardiac hypertrophy. J Mol Cell Cardiol. 2016;97:245-262.

15. Li X, Matta SM, Sullivan RD, Bahouth SW. Carvedilol reverses cardiac insufficiency in AKAP5 knockout mice by normalizing the activities of calcineurin and CaMKII. Cardiovasc Res. 2014;104(2):270-279.

16. Nichtova Z, Novotova M, Kralova E, Stankovicova T. Morphological and functional characteristics of models of experimental myocardial injury induced by isoproterenol. Gen Physiol Biophys. 2012;31(2): $141-151$.

17. Kuok QY, Yeh CY, Su BC, et al. The triterpenoids of Ganoderma tsugae prevent stress-induced myocardial injury in mice. Mol Nutr Food Res. 2013;57(10):1892-1896.

18. Rizzi E, Guimaraes DA, Ceron CS, et al. $\beta 1$-Adrenergic blockers exert antioxidant effects, reduce matrix metalloproteinase activity, and improve renovascular hypertension-induced cardiac hypertrophy. Free Radic Biol Med. 2014;73:308-317.

19. Wallner M, Duran JM, Mohsin S, et al. Acute Catecholamine exposure causes reversible myocyte injury without cardiac regeneration. Circ Res. 2016;119(7):865-879.

20. Yang C, Yang H, Wu J, et al. No overt structural or functional changes associated with PEG-coated gold nanoparticles accumulation with acute exposure in the mouse heart. Toxicol Lett. 2013;222(2):197-203.

21. Yang L, Jia Z, Yang $\mathrm{K}$, et al. Exercise protects against chronic $\beta$-adrenergic remodeling of the heart by activation of endothelial nitric oxide synthase. PLoS One. 2014;9(5):e96892.

22. Yin $\mathrm{Q}$, Yang $\mathrm{C}, \mathrm{Wu} \mathrm{J}$, et al. Downregulation of $\beta$-adrenoceptors in isoproterenol-induced cardiac remodeling through hur. PLoS One. 2016;11(4):e0152005.

23. Chowdhury I, Thompson WE, Thomas K. Prohibitins role in cellular survival through Ras-Raf-MEK-ERK pathway. J Cell Physiol. 2014; 229(8):998-1004.

24. Vidal M, Wieland T, Lohse MJ, Lorenz K. $\beta$-Adrenergic receptor stimulation causes cardiac hypertrophy via a G $\beta \gamma /$ Erk-dependent pathway. Cardiovasc Res. 2012;96(2):255-264.

25. Morisco C, Marrone C, Galeotti J, et al. Endocytosis machinery is required for $\beta 1$-adrenergic receptor-induced hypertrophy in neonatal rat cardiac myocytes. Cardiovasc Res. 2008;78(1):36-44

26. Morisco C, Zebrowski DC, Vatner DE, Vatner SF, Sadoshima J. $\beta$-Adrenergic cardiac hypertrophy is mediated primarily by the $\beta 1$-subtype in the rat heart. J Mol Cell Cardiol. 2001;33(3):561-573.
27. Cui Y, Zhao Y, Tian Y, Zhang W, Lü X, Jiang X. The molecular mechanism of action of bactericidal gold nanoparticles on Escherichia coli. Biomaterials. 2012;33(7):2327-2333.

28. Singh V, Nair SP, Aradhyam GK. Chemistry of conjugation to gold nanoparticles affects G-protein activity differently. JNanobiotechnology. 2013;11:7.

29. van Vuren EJ, Malan L, von Känel R, Cockeran M, Malan NT. Hyperpulsatile pressure, systemic inflammation and cardiac stress are associated with cardiac wall remodeling in an African male cohort: the SABPA study. Hypertens Res. 2016;39(9):648-653.

30. Zhao L, Cheng G, Jin R, et al. Deletion of interleukin-6 attenuates pressure overload-induced left ventricular hypertrophy and dysfunction. Circ Res. 2016;118(21):1918-1929.

31. Kumar S, Seth S, Jaiswal A, et al. Chronic beta-adrenergic activationinduced left ventricular systolic dysfunction is associated with systemic release of TNF-alpha and IL-1-beta in rats. Pharmacol Rep. 2009; 61(5):870-876.

32. Nagoor Meeran MF, Jagadeesh GS, Selvaraj P. Thymol attenuates inflammation in isoproterenol induced myocardial infarcted rats by inhibiting the release of lysosomal enzymes and downregulating the expressions of proinflammatory cytokines. Eur J Pharmacol. 2015;754: 153-161.

33. Goebel MU, Mills PJ, Irwin MR, Ziegler MG. Interleukin-6 and tumor necrosis factor-alpha production after acute psychological stress, exercise, and infused isoproterenol: differential effects and pathways. Psychosom Med. 2000;62(4):591-598.

34. Chen H, Dorrigan A, Saad S, Hare DJ, Cortie MB, Valenzuela SM. In vivo study of spherical gold nanoparticles: inflammatory effects and distribution in mice. PloS One. 2013;8(2):e58208.

35. Gutkind GS, Offermanns S. A new G(q)-initiated MAPK signaling pathway in the heart. Dev Cell. 2009;16(2):163-164.

36. Bueno OF, De Windt LJ, Tymitz KM, et al. The MEK1-ERK1/2 signaling pathway promotes compensated cardiac hypertrophy in transgenic mice. EMBO J. 2000;19(23):6341-6350.

37. Fu Y, Xiao H, Zhang Y. Beta-adrenoceptor signaling pathways mediate cardiac pathological remodeling. Front Biosci (Elite Ed). 2012; 4:1625-1637.

38. Son Y, Cheong YK, Kim NH, Chung HT, Kang DG, Pae HO. Mitogenactivated protein kinases species: how can ROS activate MAPK pathways? J Signal Transduct. 2011;2011:792639.

39. Arad M, Seidman CE, Seidman JG. AMP-activated protein kinase in the heart: role during health and disease. Circ Res. 2007;100(4): 474-488.

40. McCubrey JA, Lahair MM, Franklin RA. Reactive oxygen speciesinduced activation of the MAP kinase signaling pathways. Antioxid Redox Signal. 2006;8(9-10):1775-1789.

41. Dyck JR, Lopaschuk GD. AMPK alterations in cardiac physiology and pathology: enemy or ally? J Physiol. 2006;574(Pt 1):95-112.

42. Shaheen TI, El-Naggar ME, Hussein JS, et al. Antidiabetic assessment; in vivo study of gold and core-shell silver-gold nanoparticles on streptozotocin-induced diabetic rats. Biomed Pharmacother. 2016;83: 865-875.

43. Dkhil MA, Bauomy AA, Diab MS, Al-Quraishy S. Antioxidant and hepatoprotective role of gold nanoparticles against murine hepatic schistosomiasis. Int J Nanomedicine. 2015;10:7467-7475.

44. Negahdary M, Chelongar R, Zadeh SK, Ajdary M. The antioxidant effects of silver, gold, and zinc oxide nanoparticles on male mice in in vivo condition. Adv Biomed Res. 2015;4:69.

45. Selim ME, Abd-Elhakim YM, Al-Ayadhi LY. Pancreatic response to gold nanoparticles includes decrease of oxidative stress and inflammation in autistic diabetic model. Cell Physiol Biochem. 2015;35(2): 586-600.

46. Takahashi H, Niidome Y, Niidome T, Kaneko K, Kawasaki H, Yamada S. Modification of gold nanorods using phosphatidylcholine to reduce cytotoxicity. Langmuir. 2006;22(1):2-5.

47. Pan Y, Neuss S, Leifert A, et al. Size-dependent cytotoxicity of gold nanoparticles. Small. 2007;3(11):1941-1949. 
48. Veronese FM, Pasut G. PEGylation, successful approach to drug delivery. Drug Discov Today. 2005;10(21):1451-1458.

49. Alkilany AM, Murphy CJ. Toxicity and cellular uptake of gold nanoparticles: what we have learned so far? J Nanopart Res. 2010;12(7): 2313-2333.
50. Fadeel B, Garcia-Bennett AE. Better safe than sorry: understanding the toxicological properties of inorganic nanoparticles manufactured for biomedical applications. Adv Drug Deliv Rev. 2010;62(3):362-374.

International Journal of Nanomedicine

\section{Publish your work in this journal}

The International Journal of Nanomedicine is an international, peerreviewed journal focusing on the application of nanotechnology in diagnostics, therapeutics, and drug delivery systems throughout the biomedical field. This journal is indexed on PubMed Central, MedLine, CAS, SciSearch $®$, Current Contents $® /$ Clinical Medicine,
Journal Citation Reports/Science Edition, EMBase, Scopus and the Elsevier Bibliographic databases. The manuscript management system is completely online and includes a very quick and fair peer-review system, which is all easy to use. Visit http://www.dovepress.com/ testimonials.php to read real quotes from published authors.

Submit your manuscript here: http://www.dovepress.com/international-journal-of-nanomedicine-journal 